\title{
Properties of adhesive tapes used for stratum corneum stripping
}

\author{
Jui-Chen Tsai ${ }^{1}$, Norman D. Weiner ${ }^{1}$, Gordon L. Flynn ${ }^{1}$ and James Ferry ${ }^{2}$ \\ 'College of Pharmacy, University of Michigan, Ann Arbor, MI 48109 (U.S.A.) and 'The Upjohn Company, Kalamazoo, MI (U.S.A.)
}

(Received 6 September 1990)

(Modified version received 22 January 1991)

(Accepted 31 January 1991)

Key words: Adhesive tape; Stratum corneum; Stripping; Transepidermal water loss

\section{Summary}

The effectiveness of three adhesive tapes, $3 \mathrm{M}^{\prime} \mathrm{s}$ No. 810 , No. 845 and No. 850 , in stripping stratum corneum from hairless mouse skin. was compared by measuring transdermal water loss (TEWL) and distribution profiles of a marker, minoxidil, from a solution formulation. While No. 850 tape failed to increase TEWL perceptively even after 24 strippings, both No. 810 and 845 tapes effectively removed the whole stratum corneum, at least as reflected in TEWL measurements. TEWL specifically increased incrementally from somewhere between 4 and $8 \mathrm{~g} / \mathrm{m}^{2}$ per h to $120 \mathrm{~g} / \mathrm{m}^{2}$ per $\mathrm{h}$. From both TEWL measurements and distribution profiles of minoxidil in skin $2 \mathrm{~h}$ post-application of its formulation, it appears that the $3 \mathrm{M}$ No. 845 tape more efficiently removes stratum comeum than $3 \mathrm{M}$ No. 810 tape. The difference between No. 810 and No. 845 tapes in stripping formulation-treated skin held in a diffusion cell was application-time dependent, since the No. 845 tape harvested no more minoxidil than the No. 810 tape at 12 and $24 \mathrm{~h}$ following application of the formulation.

\section{Introduction}

Tape stripping is a technique which has been found useful in dermatological research for selectively and at times exhaustively removing the skin's stratum corneum. Such stripped skin has itself been used as a standardized injury in wound healing research (Pinkus, 1951, 1952). Stripping has also been adapted for studying epidermal growth kinetics (Downes et al., 1967; Porter and Shuster, 1967) and various aspects of skin permeability (Blank, 1953; Monash, 1957; Monash and Blank. 1958). With regard to the latter, differences in the

Correspondence: G.L. Flynn, College of Pharmacy, University of Michigan, Ann Arbor, MI 48109-1065, U.S.A. permeability of intact skin and fully stripped have provided us with estimates of the diffusional resistance within the skin which is over and above that of the horny layer (Flynn et al., 1981; Behl et al., 1983).

Stripping has typically been done with the first-found, most conveniently available tape. Only recently has it been realized that marked, experimentally relevant differences exist in the stripping efficiencies and other experimentally important properties of commonly available tapes. Of particular note, it was recently reported that $3 \mathrm{M}$ 's No. 810 (Scotch $^{\text {TM }}$ Brand Magic Tape, 3M Co., Minneapolis, MN) tape. a cellulose-backed adhesive tape, while a good stripping medium, is too hygroscopic for the stratum corneum tissue adhering to it to be accurately weighed (Han et al., 
1989-1990). The hygroscopicity obviates its use in experiments which require quantitative stripping. Another adhesive tape formed on a polyester film, $3 \mathrm{M}$ 's No. 850 tape, was amenable to tissue weight determination, but apparently it only removed loosely adhering, surface squames even irrespective of repetitive stripping (Han et al., 1989-1990). Thus, there still exists a need for a non-hygroscopic tape capable of lifting off all the horny layer and which also allows quantification of the adhering tissue by weight difference. In this note we report on a polypropylene tape, $3 \mathrm{M}$ 's No. 845 , which seems to offer the sought-after properties. This tape affords quantitative study of the deposition of a drug into the horny layers as a function of the depth of stripping.

\section{Materials and Methods}

\section{Hairless mice}

Male mice (SKh-hr-1, Central Animal Facility, Temple University, Philadelphia, PA) between 60 and 90 days of age were used. To ensure that the skin of the animals would be free of bite-marks and similar defects, they were housed individually for not less than 7 days prior to starting the experiments. This is a reasonable time since the stratum corneum is turned over completely in less than 5 days (Han et al., 1989-1990).

\section{$\left[{ }^{3} H\right]$ Minoxidil formulation}

Deposition experiments were performed using a $\left[{ }^{3} \mathrm{H}\right]$ minoxidil solution in a propylene glycol/ ethanol/water solvent composition $(20: 60: 20$ $\mathrm{v} / \mathrm{v}$ ). $\left[{ }^{3} \mathrm{H}\right]$ Minoxidil with a specific activity of 44 $\mathrm{Ci} / \mathrm{mmol}$ was provided by The Upjohn Co. (Kalamazoo, MI) for our purposes. The solution formulated from it contained only the radiolabeled drug and had an activity of $0.2 \mu \mathrm{Ci} / \mathrm{ml}$, and a concentration of less than $1 \mathrm{ng} / \mathrm{ml}$. Based on studies to be reported independently, the concentration is far too low to experience minoxidil precipitation as the formulation evaporates.

\section{Transepidermal water loss on stripped skin}

Changes in the rate of transepidermal water loss (TEWL) through the skin as a function of the degree of stripping were evaluated on an Evaporimeter (EP1 Evaporimeter, Servomed, Stockholm, Sweden). The mice were first anesthetized with urethane ( $1.5 \mathrm{mg}$ per g body weight) by intraperitoneal injection. An animal was then placed in a draft-free, protected chamber, a converted glove box, and the Evaporimeter probe was placed over the lateral-dorsal skin site to be stripped. A TEWL reading was taken on the intact skin. It took one to two minutes for the instrument to stabilize before taking this and subsequent readings. Stripping was then performed by pressing one of the adhesive tapes, either $3 \mathrm{M}$ 's No. $810,3 \mathrm{M}$ 's No. 845 or 3M's No. 850 , against the demarcated dorsal-lateral site and gently smoothing the tape with the fingers to cause it to adhere evenly. The strip was then abruptly peeled from the skin surface. This stripping process was repeated, then a second TEWL reading was taken. Eleven further dual strippings, all at the same site with fresh pieces of a given tape, were performed and each pair of strippings was followed by a TEWL reading. Changes in TEWL were put in terms of the increase in TEWL over the initial control reading. Three mice were used with each type of tape and the TEWL results, appearing in Fig. 1, were averaged.

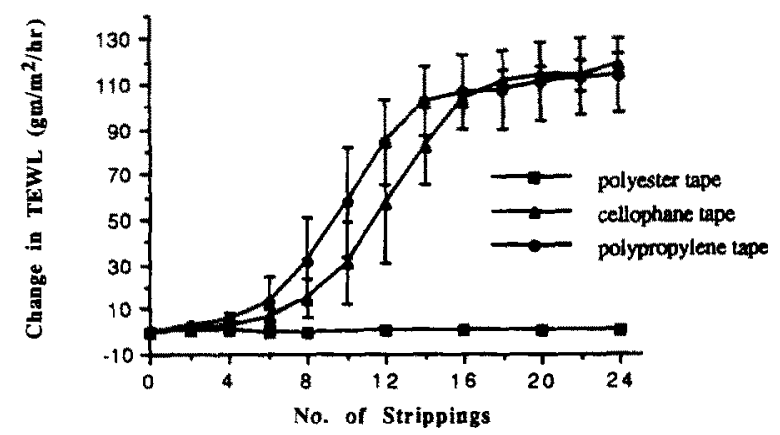

Fig. 1. Transdermal water loss (TEWL) from the dorsal-lateral surface of hairless mice following repetitive stripping with polyester, cellophane and polypropylene tapes. Each data point represents mean \pm standard deviation ( $n=3$ ) 
Distribution profiles of minoxidil in strippings from excised skin

Skin sections were excised from the dorsal and abdominal areas of freshly sacrificed (spinal cord dislocation) hairless mice and mounted on the Franz-type cells. $125 \mu \mathrm{l}$ of the solution containing the $\left[{ }^{3} \mathrm{H}\right]$ minoxidil were applied to the exposed skin $\left(1.77 \mathrm{~cm}^{2}\right.$ in area) in each cell in the manner described previously (Tsai et al., 1991) after having first filled the receiver compartment of the cell with isotonic $\mathrm{pH} 7.4$ phosphate buffer. The application was left open to the atmosphere. After either 2,12 or $24 \mathrm{~h}$, skin sections were removed from sets of the diffusion cells, rinsed with $2 \mathrm{ml}$ of $70 \%$ alcohol from a syringe for about $20 \mathrm{~s}$, and pinned to a board so that they were taut and smooth-surfaced. We are aware that the method of rinsing can affect the quantitative outcomes of deposition. It was clearly shown that this procedure recovers all minoxidil immediately after application of the formulation. Three pieces of skin were taken at each specified time, stripped and counted and the results, appearing in Fig. 2, were averaged. These were anchored to a board with four push-pins, one each at all the corners of a tissue section. A piece of adhesive tape (either 3M's No. 810 or 3 M's No. 845) was then applied over the treated area, pressed tightly to the skin, and abruptly pulled away. The strip was folded inward toward its adhesive surface, placed into and sealed in a scintillation vial, and then chemically digested and incinerated in a tissuc oxidizer (Model 306 Packard Oxidizer, Packard Instrument Co., Downers Grove, IL). Nine more strippings were done in identical fashion on each section. The tissue oxidizer converted the ${ }^{3} \mathrm{H}$ label to ${ }^{3} \mathrm{H}_{2} \mathrm{O}$, which was condensed and collected in the tritium sample vial and Monophase S (Packard Instrument $C_{0}$.) was added as scintillator. The samples were then assayed in a liquid scintillation counter (Beckman LS 9000, Beckman Instruments, Fullerton, CA), using the ${ }^{3} \mathrm{H}$ channel.

\section{Results and Discussion}

Transepidermal water loss measurements have been used by many researchers as an indicator of the barrier competency of the skin. Broken and otherwise barrier defective areas of skin evidence
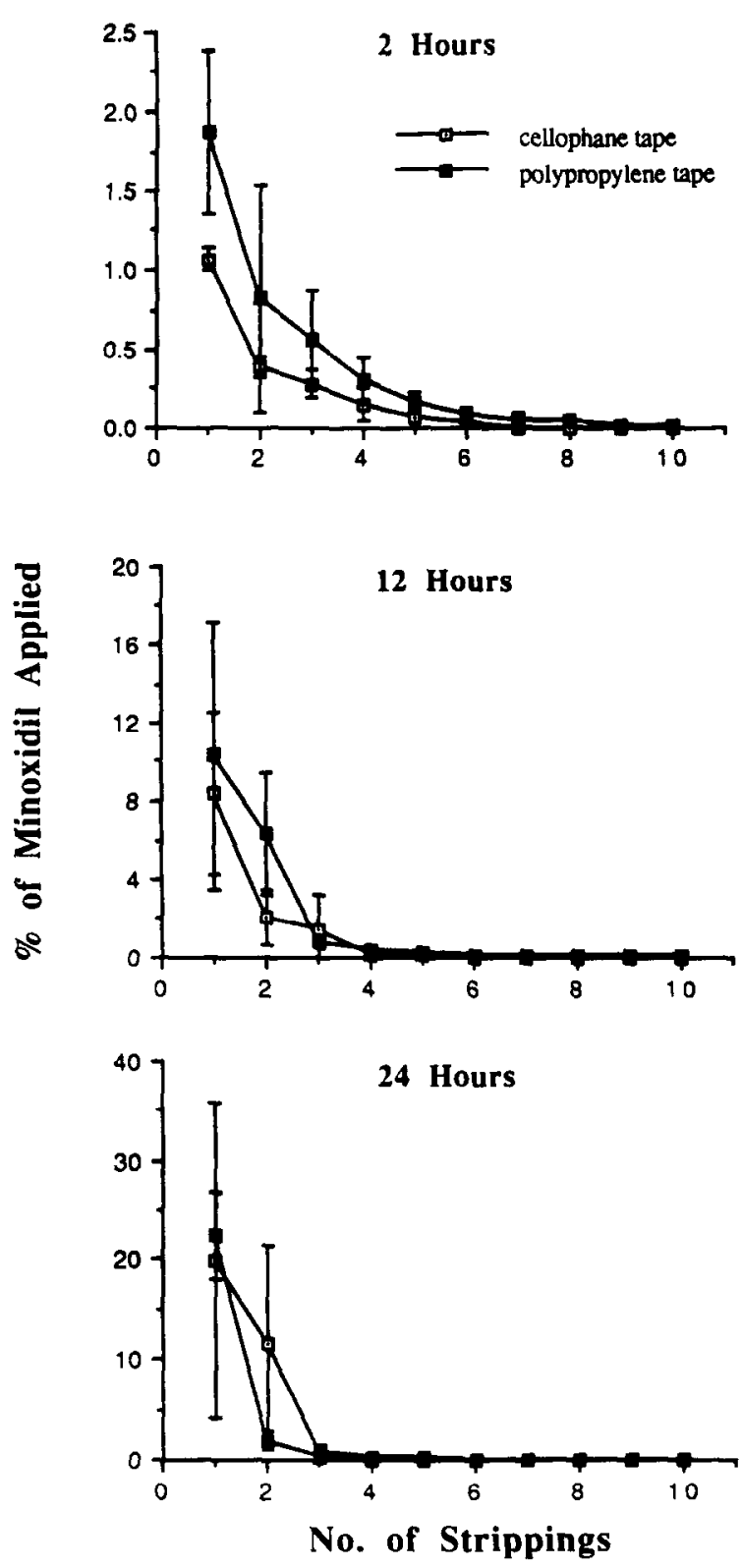

Fig. 2. Distribution profiles of minoxidil in 10 strippings from skin applied with $125 \mu 1$ trace $\left[{ }^{3} \mathrm{H}\right.$ ]minoxidil in propylene glycol/ethanol/water $(20: 60: 20 \mathrm{v} / \mathrm{v})$ system for 2,12 and 24 h. Strippings were made by cellophane and polypropylene tapes. Each data point represents mean \pm standard deviation $(n=3)$. 
high rates of water loss, as much as 20-25 times greater than observed over normal skin. In the present studies all control TEWL readings fell within the range $4-8 \mathrm{~g} / \mathrm{m}^{2}$ per $\mathrm{h}\left(0.4-0.8 \mathrm{mg} / \mathrm{cm}^{2}\right.$ per h) range. As seen in Fig. 1, two tapes, the cellophane (No. 810) tape and the polypropylene (No. 845) tape, removed most if not all of the stratum corneum. This is evident from the fact that the TEWL values reached their upper attainable limit of $120 \mathrm{~g} / \mathrm{m}^{2}$ per $\mathrm{h}$ after 15 or so strippings. Thus, TEWL increases over the control value of $110-115 \mathrm{~g} / \mathrm{cm}^{2}$ per $\mathrm{h}$ were observed. In stark contrast, repeated stripping with 3M's No. 850 tape failed to increase TEWL perceptively even after 24 strippings, confirming the recent observations of Han et al. (1990) concerning this tape. The failure of this tape to elevate TEWL is certain evidence that the stratum corneum remains intact. On the other hand, Han et al. (1989-1990) showed a single daily stripping with the polyester tape removes about $30 \mathrm{mg}$ of tissue per $\mathrm{cm}^{2}$, day after day. The polypropylene tape used in these experiments lifts off up to six times as much tissue on the first stripping (Tsai et al., 1991). In this regard, because of the hygroscopicity of 3M's 810 tape, there are no available comparisons.

It is evident from the leftwardly displaced curve in Fig. 1 that 3M's No. 845 tape is slightly more forceful in removing stratum corneum, at least in the first several strippings, than the commonly used cellulosic tape. Note that it takes about two more strippings with the latter tape to attain the same level of TEWL elevation. The total shifting of the curves from the fourth stripping to the fourteenth is statistically meaningful (two-way analysis of variance, $p<0.005$ ) even though $t$-tests at the specific values of the repetitive strippings fail to evidence a statistical difference (significance $=0.200-0.368$ ). It is notable that the difference in the abilities of these two tapes to remove stratum corneum shows up again in the minoxidil deposition experiments. The maximum increase in TEWL was the same for both tapes, meaning that each effectively removes the full stratum corneum, at least functionally.

The deposition of minoxidil from its vehicle into the stratum corneum as a function of length of application time of the vehicle (and length of time of a skin section in a diffusion cell) as determined by drug picked up by tape stripping is illustrated in the three frames of Fig. 2. After $2 \mathrm{~h}$ application time, the distribution of minoxidil appears to decrease smoothly from the surface of the stratum corneum to its interior irrespective of whether the No. 845 tape or the No. 850 tape was used in the stripping. Moreover, the procedure scems reproducible bascd on the surprisingly low standard deviations (bars about the data points). More minoxidil is removed at each number of stripping by the polypropylene tape than the cellophane tape, but the significance levels obtained by $t$-tests at each specific number of strippings range from 0.001 to 0.359 . However, the total curves suggest that the 3M's No. 845 tape provides more efficient stripping as the minoxidil recovered with this tape is greater each subsequent (two-way analysis of variance, $p<0.001$ ).

At both the 12 and $24 \mathrm{~h}$ application times the minoxidil appears to be concentrated in only the first two to three strippings. Moreover, it does not appear that the polypropylene tape is lifting off more stratum corneum than its cellulosic counterpart at these times. One might be led to the conclusion that the gradients of minoxidil within the stratum corneum at these treatment times are more steep than seen at $2 \mathrm{~h}$, a conclusion which has to be tempered by recognizing the very real possibility that more tissue may be being removed in the early strippings at 12 and $24 \mathrm{~h}$. This suggests that conditioning of the skin in the diffusion chamber changes its stripping responses. This dilemma in the interpretation is now being investigated and resolved (Tsai et al., 1991).

The present experiments substantiate the validity of using TEWL measurements to reveal the integrity of the skin barrier in live animals. However, since TEWL readings with the Evaporimeter are influenced by volatile solvents other than water, it does not appear that it will be possible to rely totally on TEWL to assess the influences of vehicles and solvent treatments on the skin. Moreover, it would be difficult to use TEWL measurements in in vitro studies without radically redesigning the typical Franz-type diffusion measuring apparatus. However, we show here that deposition experiments might offer keen insight into the roles 
of vehicles. Whether or not this proves possible depends on how reproducibly the skin strips after different vehicle treatments. This situation can be clarified if the mass of tissue adhering to the tape-strip can be accurately determined, and it appears this will be possible with the polypropylene tape.

\section{Acknowledgement}

This study was supported by The Upjohn Co., Kalamazoo, MI.

\section{References}

Behl. C.R., Linn, E.E., Flynn, G.L.. Pierson, C.L., Higuchi. W.I. and Ho, N.F.H.. Permeation of skin and eschar by antiseptics. I: Baseline studies with phenol. J. Pharm. Sci., 72 (1983) $391-397$.

Blank, I.H.. Further observations on factors which influence the water content of the stratum corneum. J. Invest. Dermatol., 21 (1953) 259-269.

Downes, A.M., Matoltsy, A.G. and Sweeney, T.M., Rate of turnover of the stratum corneum in hairless mice. $J$. Invest. Dermatol., 49 (1967) 400-405.
Flynn, G.L., Dürrheim, H. and Higuchi, W.I., Permeation of hairless mouse skin II: Membrane sectioning techniques and influence on alkanol permeabilities. J. Pharm. Sci., 70 (1981) 52-56.

Han, S.-T.R., Haberkamp, M. and Flynn, G.L., Epidermal kinetics and skin condition: I. Stripping technique for quantitating stratum corneum turnover in hairless mouse skin. J. Tuxicol. - Cut. \& Ocular Toxicol., 8 (1989-1990) $539-553$.

Monash, S., Location of the superfacial epithelial barrier to skin penetration. J. Invest Dermatol., 29 (1957) 367-376.

Monash, S., and Blank, I.H., Location and reformation of the epithelial barrier to water vapor. Arch. Dermatol., 78 (1958) 710-714.

Pinkus, H., Examination of the epidermis by the strip method of removing horny layers. I. Observations on thickness of the horny layer, and on mitotic activity after stripping. $J$. Invest. Dermatol, 16 (1951) 383-386.

Pinkus, H., Examination of the epidermis by the strip method. II. Biometric data on regeneration of the human epidermis. J. Invest. Dermatol., 19 (1952) 431-447.

Porter, D., and Shuster, S., A new method for measuring replacement of epidermis and stratum corneum in human skin. J. Invest. Dermatol., 49 (1967) 251-255.

Tsai, J.C., Weiner, N.D. and Flynn, G.L., Solvent effects on the harvesting of stratum corneum from hairless mouse skin through adhesive tape stripping in vitro. Int. I. Pharm., 68 (1991) 127-133. 